
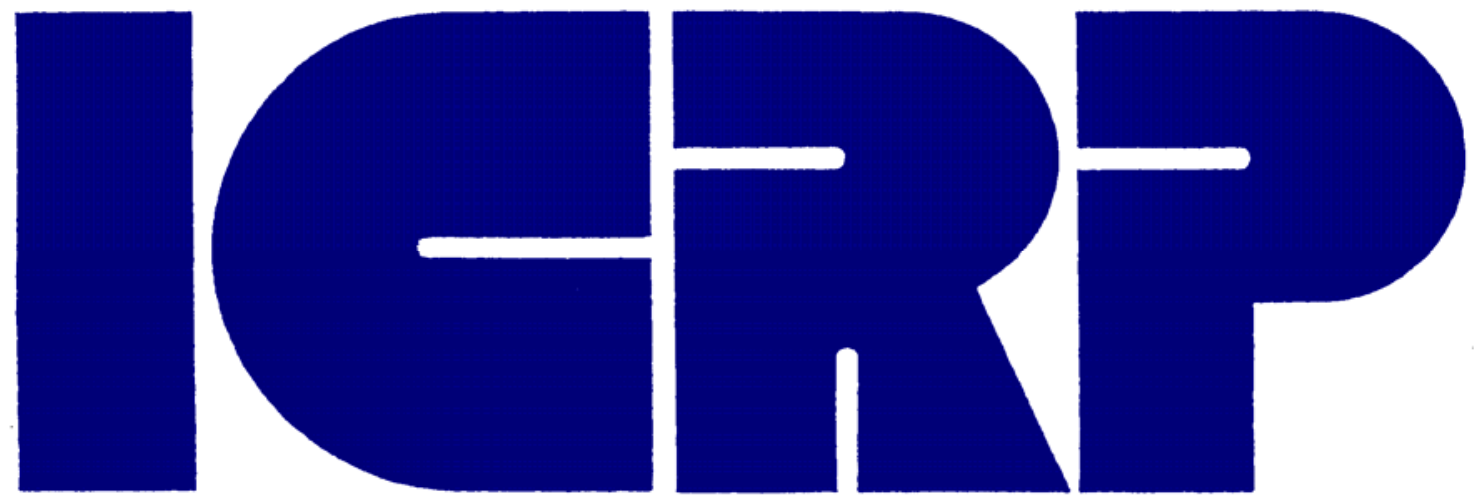

2004 Annual Report of the

\title{
International Commission \\ on Radiological Protection
}
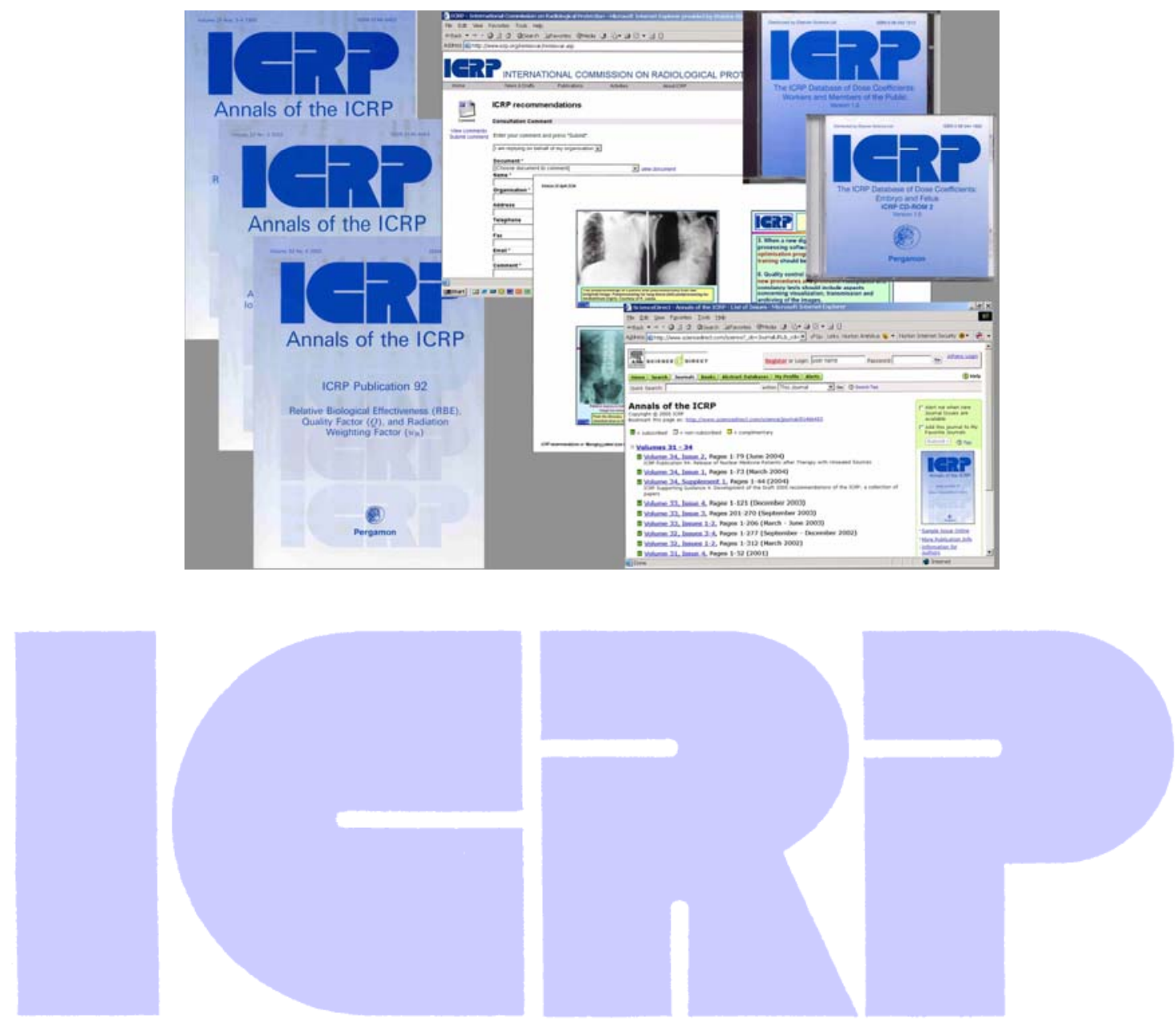
ICRP Annual Report on 2004

2005-05-20

ICRP Reg. No. 52/150/05

Cover collage: ICRP products....

...showing printed ICRP Publications, ICRP CD-ROMs with the ICRP database of dose coefficients, the Comments page of the ICRP web site (used for public consultation on all ICRP reports), a sample page from one of the cost-free ICRP educational slide sets, and the ICRP page at www.sciencedirect.com where electronic versions of ICRP reports can be downloaded. 


\section{Our Mission Statement}

The International Commission on Radiological Protection, ICRP, is an independent Registered Charity, established to advance for the public benefit the science of radiological protection, in particular by providing recommendations and guidance on all aspects of protection against ionising radiation.

\section{Chairman's Foreword}

The Main Commission met twice in 2004 and the main topic was the preparation of the next recommendations. The first meeting was in Vienna in April and the draft of the 2005 proposed recommendations was agreed for web consultation. That consultation for, unusually, a six month period resulted in about 200 responses amounting to some 600 pages of text! It is very pleasing to the Commission that so much effort was devoted around the world to commenting on the proposals. The commission now has to assess the comments and decide on the next stage of the work.

The second meeting was of the Commission and its Committees in Beijing during October with the Commission also subsequently meeting during a visit to Suzhou. This was the last meeting of the Committees in their 2001-2005 term. The membership of the new Commission and Chairmen of Committees 2005-2009 was decided, see the Table below:

\begin{aligned} & \hline Position in the Main Commission Name \\ & \hline Chairman Lars-Erik Holm (Sweden) \\ & Vice-Chairman Roger Cox (UK) \\ & Committee Chairpersons: \\ & C1 (Biological Effects) Julian Preston (USA) \\ & C2 (Dosimetry) Christian Streffer (Germany; -2007) \\ & Hans-Georg Menzel (Switzerland, 2007-9) \\ & C3 (Medicine) Fred Mettler (USA) \\ & C4 (Applications) Annie Sugier (France) \\ & C5 (Environment) Jan Pentreath (UK) \\ & Other members John Boice (USA) \\ & Abel González (Argentina) \\ & Jai-Ki Lee (Korea) \\ & Yasuhito Sasaki (Japan) \\ & Nataliya Shandala (Russia) \\ & Zi Qiang Pan (China) \\ & Jack Valentin (Sweden) \\ & \hline\end{aligned}


During the year I participated in several meetings to present the programme of work of the Commission. I attended the International Conference on radiation protection and shielding in Madeira in May, the Vice-Chairman and I gave presentations to ISCORS in Washington in July, I participated in the Senior regulators meeting at the General conference of the IAEA in Vienna in September, the EC Article 31 seminar on the new Recommendations in November as well as the NEA CRPPH expert Group also in November.

But the main focus of the work has been on the next Recommendations and on the Foundation Documents that will underpin them. The list of foundation Documents now extends to significant texts on the Biological effects of radiation, the Dosimetry aspects of Protection, the definition of the 'individual' for the purposes of setting and assessing compliance with standards, and a treatise on the approach to Optimization of Protection.

In addition the Commission approved a comprehensive report on the risks of low doses of radiation for consultation on the web. This makes a total, so far, of five documents supporting the recommendations. The Commission is considering whether additional foundation documents are required.

This will be my last Annual report and I will leave the Commission after some 20 years continuous service. I wish my successors well!

Roger H Clarke

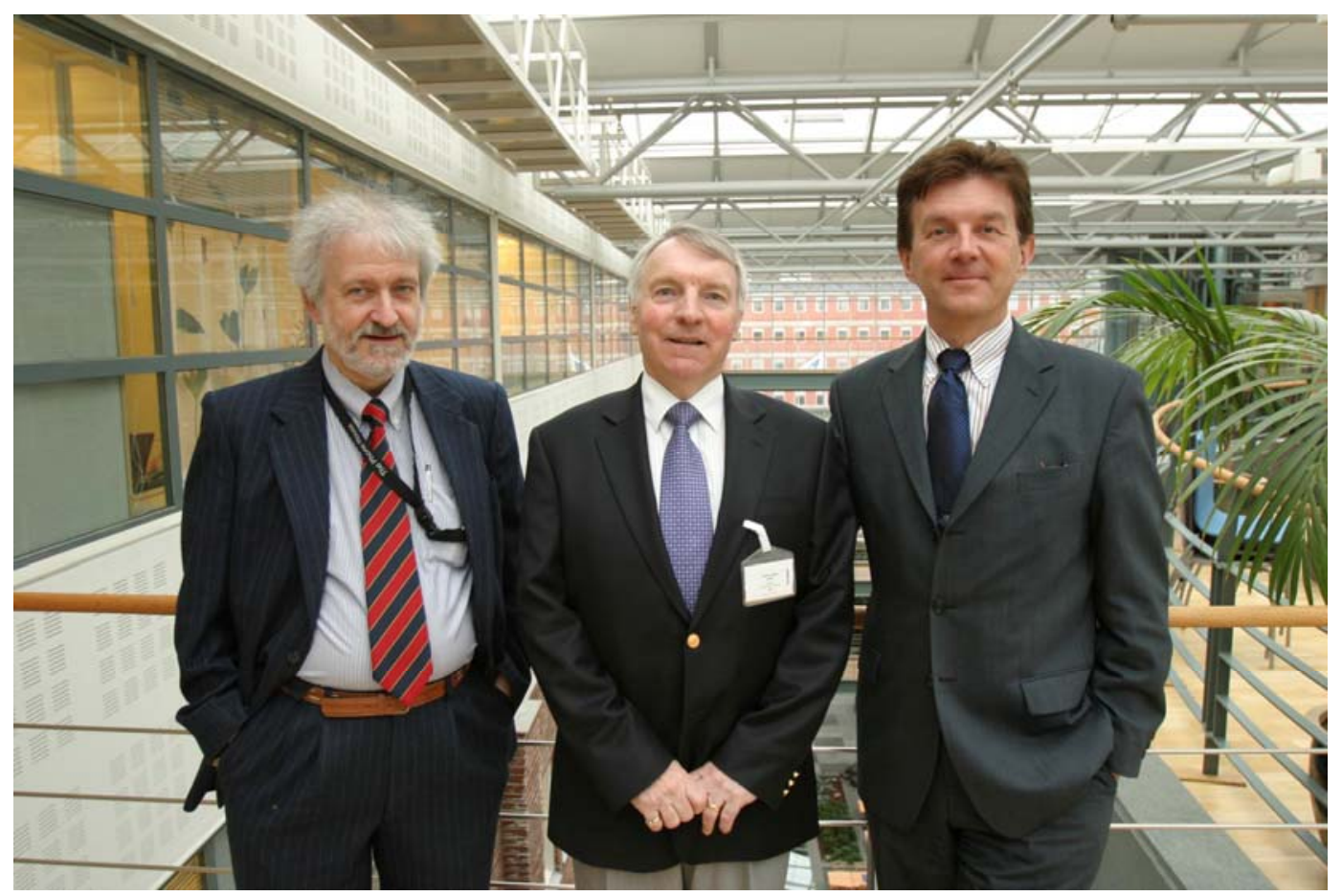

Professor Roger H Clarke (in the middle), leaving Chairman of ICRP, Dr Lars-Erik Holm (right), Chairman-elect, and Dr Jack Valentin (left), Scientific Secretary, at the Swedish Radiation Protection Authority in Stockholm, spring 2005 


\section{The International Commission on Radiological Protection}

The primary body in radiological protection is ICRP. It was formed in 1928, by the International Congress of Radiology, as the 'International X-ray and Radium Committee', but adopted its present name in 1950 to reflect its growing involvement in areas outside that of occupational exposure in medicine, where it originated.

\section{Broad structure}

ICRP consists of the Main Commission, Committee 1 (Radiation Effects), Committee 2 (Doses from Radiation Exposure), Committee 3 (Protection in Medicine), Committee 4 (Application of ICRP Recommendations), ad hoc Task Groups and Working Parties, and the Scientific Secretariat.

From 1 July 2005, there will be a fifth Committee concerned with protection of the environment.

\section{Membership}

The Main Commission consists of twelve members and a Chairman, while the Committees contain between 15 and 20 members each.

The Commission and its Committees run for four-year periods, from 1 July. On each occasion of a new period, at least three, and not more than five, members of the Commission must be changed. A similar rate of renewal is sought for the Committees. Such a new period began 1 July 2001, and the autumn 2004 meetings of the Commission and its Committees was the last time that the full set of members of the 2001 - 2005 term met.

\section{Meetings}

The Commission meets once or twice a year. Each Committee meets once a year. Twice in each four-year period, the annual meeting of the Committees is conducted jointly and together with the Commission. These meetings are funded as necessary from monies available to ICRP.

\section{Financing}

The activities of ICRP are financed mainly by voluntary contributions from national and international bodies with an interest in radiological protection. (A list of the bodies providing such contributions in 2000 is appended at the end of this report). Some additional funds accrue from royalties on ICRP Publications. Members' institutions also provide support to ICRP by making the members' time available without charge and, in many cases, contributing to their costs of attending meetings.

\section{Mode of operation}

The Commission uses Task Groups and Working Parties to deal with specific areas. Task Groups are formally appointed by the Commission to perform a defined task, usually the preparation of a draft report. A Task Group usually contains a majority of specialists from outside the Commission's structure. It is funded as necessary from monies available to ICRP.

Working Parties are set up by Committees to develop ideas, sometimes leading to the establishment of a Task Group. The membership of a Working 
Party is usually limited to Committee members. Working Parties receive no funding of their own, i.e. they operate primarily by correspondence and by meetings in direct conjunction with meetings of the Committee concerned.

These activities are co-ordinated with a minimum of bureaucracy by a Scientific Secretary, ensuring that ICRP recommendations are promulgated.

Thus, ICRP is an independent international network of specialists in various fields of radiological protection. At any one time, about one hundred eminent scientists are actively involved in the work of ICRP. The four-tier structure described provides a rigorous Quality Management system of peer review for the production of ICRP Publications.

Furthermore, before draft ICRP reports are approved for publication, they are regularly circulated to a number of bodies and individual experts, and posted for public consultation on the Internet.

\section{Objective}

In preparing its recommendations, the Commission considers the fundamental principles and quantitative bases on which appropriate radiation protection measures can be established, while leaving to the various national protection bodies the responsibility of formulating the specific advice, codes of practice, or regulations that are best suited to the needs of their individual countries.

The aim of the recommendations of ICRP is to

- provide an appropriate standard of protection for mankind from sources of ionising radiation, without unduly limiting beneficial practices that give rise to exposure to radiation.

\section{Structure of ICRP}

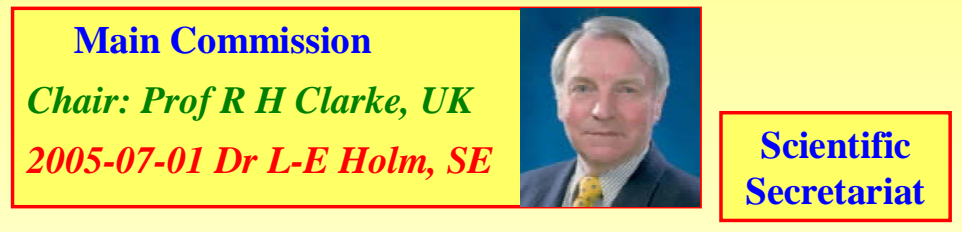

C1- Radiation Effects Dr R Cox, UK 2005-07-01 Dr J Preston, US

C2- Doses from Radiation Exposure Prof C Streffer, DE 2007-07-01 Dr H-G Menzel, CH

C3- Protection in Medicine Prof F Mettler, US

C4- Application of ICRP Recommendations Dr A Sugier, F

Task Groups 2005: C5- Environment Prof J Pentreath, UK

Working Parties

INTERNATIONAL COMMISSION ON RADIOLOGICAL PROTECTION

The structure of ICRP currently comprises a Main Commission and four Committees (from 1 July 2005, five Committees; there were also five Committees 1950 - 1962). 
- 4 (26) - 


\section{The Work Programme of the Commission and its Committees:}

The Commission is an independent Registered Charity, established to advance for the public benefit the science of radiological protection, in particular by providing recommendations and guidance on all aspects of protection against ionising radiation.

Committee 1 considers the risk of induction of cancer and heritable disease (stochastic effects) together with the underlying mechanisms of radiation action; also, the risks, severity, and mechanism of induction of tissue/organ damage and developmental defects (deterministic effects).

Committee 2 is concerned with the development of dose coefficients for the assessment of internal and external radiation exposure, development of reference biokinetic and dosimetric models, and reference data for workers and members of the public.

Committee 3 is concerned with protection of persons and unborn children when ionising radiation is used for medical diagnosis, therapy, or for biomedical research; also, assessment of the medical consequences of accidental exposures.

Committee 4 is concerned with providing advice on the application of the recommended system of protection in all its facets for occupational and public exposure. It also acts as the major point of contact with other international organisations and professional societies concerned with protection against ionising radiation.

Committee 5 will be established from 1 July 2005. It will be concerned with radiological protection of the environment. It will aim to ensure that the development and application of approaches to environmental protection are compatible with those for radiological protection of man, and with those for protection of the environment from other potential hazards.

The Main Commission of ICRP met twice in 2004: In Vienna, Austria, in April and in October in China: first in Beijing together with the four standing Committees, and immediately thereafter in Suzhou. The main issue at these meetings was the continued preparation of a set of draft fundamental ICRP Recommendations, intended to replace the current (1990) Recommendations. The new draft was subjected to world-wide public consultation in the second half of 2004.

\section{New publications}

Two reports were published as 2004 issues of the Annals of the ICRP. These are:

- Publication 93: Managing patient dose in digital radiology; and
- Publication 94: Release of patients after therapy with unsealed radionuclides. 
Digital radiology: ICRP Publication 93 points out that digital techniques have the potential to improve the practice of radiology but they also risk the overuse of radiation. The main advantages of digital imaging, i.e. wide dynamic range, post processing, multiple viewing options, and electronic transfer and archiving possibilities, are clear but overexposures can occur without an adverse impact on image quality. In conventional radiography, excessive exposure produces a 'black' film. In digital systems, good images are obtained for a large range of doses. It is very easy to obtain (and delete) images with digital fluoroscopy systems, and there may be a tendency to obtain more images than necessary.

In digital radiology, higher patient dose usually means improved image quality, so a tendency to use higher patient doses than necessary could occur. Different medical imaging tasks require different levels of image quality, and doses that have no additional benefit for the clinical purpose should be avoided.

Image quality can be compromised by inappropriate levels of data compression and/or post-processing techniques. All these new challenges should be part of the optimisation process and should be included in clinical and technical protocols.

Local diagnostic reference levels should be re-evaluated for digital imaging, and patient dose parameters should be displayed at the operator console. Frequent patient dose audits should occur when digital techniques are introduced. Training in the management of image quality and patient dose in digital radiology is necessary. Digital radiology will involve new regulations and invoke new challenges for practitioners. As digital images are easier to obtain and transmit, the justification criteria should be reinforced.

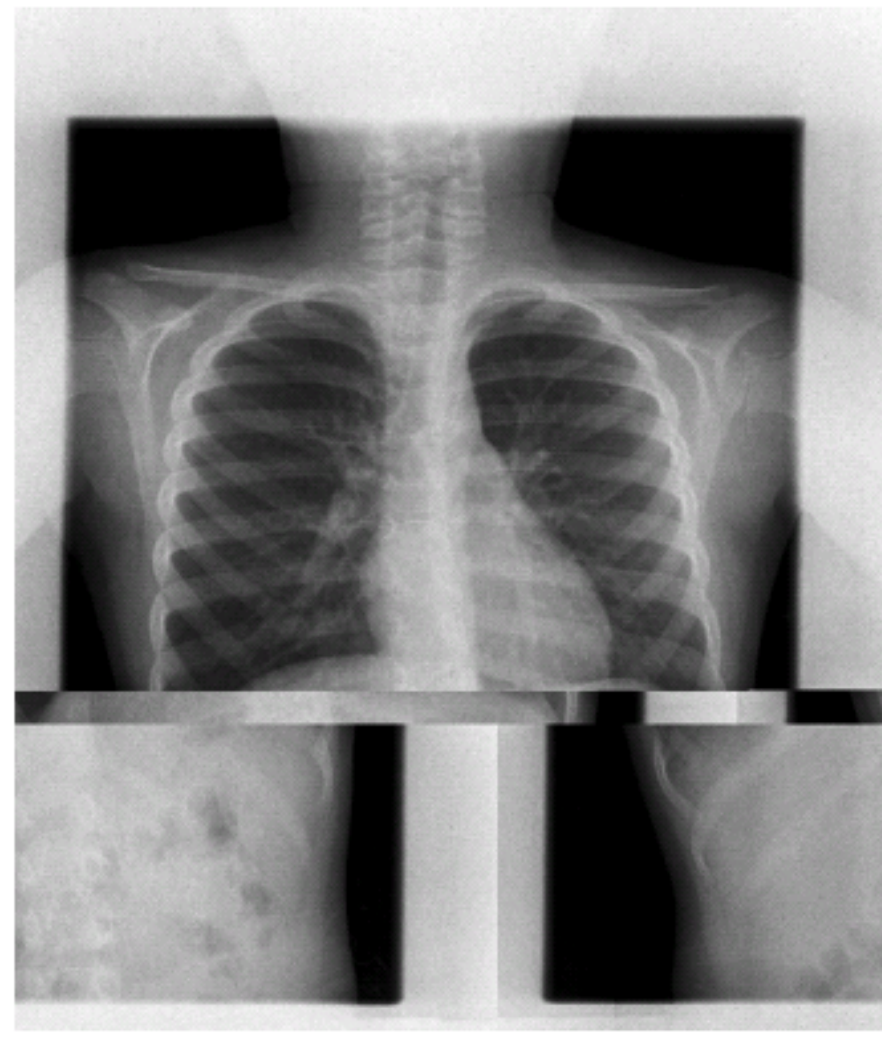

This Figure from ICRP Publication 94 shows an extreme example of a failure due to a hard disk error. Many other problems and possibilities, many of them more subtle than this, are also discussed in the report. 
Commissioning of digital systems should involve clinical specialists, medical physicists, and radiographers to ensure that imaging capability and radiation dose management are integrated. Quality control requires new procedures and protocols (visualisation, transmission, and archiving of the images).

Nuclear medicine therapy: It is pointed out in ICRP Publication 94 that after some therapeutic nuclear medicine procedures with unsealed radionuclides, precautions may be needed to limit doses to other people, but this is rarely the case after diagnostic procedures. Iodine-131 results in the largest dose to medical staff, the public, caregivers, and relatives. Other radionuclides used in therapy are usually simple beta emitters (e.g. phosphorus-32, strontium-89, and yttrium-90) that pose much less risk. Dose limits apply to exposure of the public and medical staff from patients. Previously, ICRP has recommended that a source-related dose constraint for optimisation of a few mSv/episode applies to relatives, visitors, and caregivers at home, rather than a dose limit. The present report recommends that young children and infants, as well as visitors not engaged in direct care or comforting, should be treated as members of the public (i.e. be subject to the public dose limit).

The modes of exposure to other people are: external exposure; internal exposure due to contamination; and environmental pathways. Dose to adults from patients is mainly due to external exposure. Contamination of infants and children with saliva from a patient could result in significant doses to the child's thyroid. It is important to avoid contamination of children and pregnant women. After radioiodine therapy, mothers must cease breastfeeding immediately. Many types of therapy with unsealed radionuclides are contraindicated in pregnant females. Women should not become pregnant for some time after radioisotope therapy. Technetium-99m dominates discharges to the environment from excreta of nuclear medicine patients, but its short half-life limits its importance. The second largest discharges, iodine-131, can be detected in the environment after medical uses but with no measurable environmental impact. Storing patients's urine after therapy appears to have minimal benefit.

Radionuclides released into modern sewage systems are likely to result in doses to sewer workers and the public that are well below public dose limits.

The decision to hospitalise or release a patient should be determined on an individual basis. In addition to residual activity in the patient, the decision should take many other factors into account. Hospitalisation will reduce exposure to the public and relatives, but will increase exposure to hospital staff. Hospitalisation often involves a significant psychological burden as well as monetary and other costs that should be analysed and justified. Patients travelling after radioiodine therapy rarely present a hazard to other passengers if travel times are limited to a few hours.

Environmental or other radiationdetection devices are able to detect patients who have had radioiodine therapy for several weeks after treatment. Personnel operating such detectors should be specifically trained to identify and deal with nuclear medicine patients. Records of the specifics of therapy with unsealed radionuclides should be maintained at the hospital and given to the patient along with written precautionary instructions. In the case of death of a patient who has had radiotherapy with unsealed radionuclides in the last few months, special precautions may be required. 
Reports in press: An additional report was approved for publication as a double issue completing the 2004 Volume of the Annals of the ICRP, but its complex data set and the thorough Quality Assurance process required in proofreading delayed the actual publication until 2005. This is:

- Publication 95: Doses to the newborn child from radionuclides ingested in mothers' milk.

Electronic distribution of reports: In addition to the printed version sent to all subscribers and a considerable number of buyers of single reports as book issues, these various reports are also available electronically through our publisher's 'ScienceDirect' service (www.sciencedirect.com).

This increases penetration of our reports through the scientific and regulatory community very significantly, and also allows for a pricing structure that takes regional differences into account. 


\section{Committee 1 (Radiation Effects):}

Committee 1 of the International Commission on Radiological Protection has the responsibility for maintaining the biological effects of ionising radiation under review and developing documents that relate such effects to the needs of radiological protection.

Input from Committee 1 on the biological effects of radiation constitutes a platform for the current ICRP project of devising a set of next fundamental Recommendations on radiological protection. The most important task for Committee 1 is to draft a 'Foundation Document' on health effects of ionising radiation. Since the publication of the 1990 Recommendations of the ICRP (Publication 60, ICRP 1991), ICRP Committee 1 has continued to maintain broad surveillance on scientific developments regarding the quantification of health effects attributable to ionising radiation exposure and the biological mechanisms that underlie these effects. Much of the output of Committee 1 is represented in ICRP Task Groups reports and Committee 1 working parties have reviewed data in other relevant areas.

The purpose of the Foundation Document report is to summarise all post1990 Committee 1 judgements relating to the health effects of radiation in order to support the development, by the Commission, of its next Recommendations. In many of the areas considered, Committee 1 had already provided specific judgements, e.g. on risk of multifactorial diseases (Publication 83) and on Relative Biological Effectiveness of different radiations (Publication 92).

However, the revision of judgements on the induction of tissue reactions, on the nominal risk coefficients for cancer and heritable disease, the transport of cancer risk between different populations, and on the choice of tissue weighting factors, required much additional work by the Committee for the Foundation Document.

An additional feature of the present work is the extent to which the accumulation of epidemiological and biological knowledge since 1990 has served to strengthen some of the judgements made in Publication 60 or, in some cases, has led to a revision in procedures for risk estimation. In spite of the detailed nature of these gains in knowledge the principal objective of this report is the provision of broad judgements for practical purposes of radiological protection.

Accordingly, much of the work of the Committee centres on the continuing use of effective dose as a radiological protection quantity for practical application in the protection of workers and the population at low levels of exposure. It is often forgotten that the ICRP quantities are restricted in their application and that organ-specific absorbed doses rather than effective dose should be used when a) doses received are close to the thresholds for tissue reactions; b) epidemiological assessments of data are being made, or c) retrospective assessments of risks are being made.

The Foundation Document is structured in the following way. It begins with a brief summary of the gains in knowledge on the biological processes that underlie the health effects of radiation exposure since 1990. This is followed by a review and updated judgements on the mechanisms and risks of radiation-induced tissue reactions. The document then 
considers the mechanisms and genetics of cancer induction, summarises previous judgements on radiation weighting factors and details new epidemiologically-based judgements on nominal risk coefficients, transport of risk, radiation detriment and tissue weighting factors. There is then a section that summarises an earlier judgement on cancer risk in-utero. The document also briefly considers non-cancer diseases after radiation. The estimation of risks of heritable disease is detailed in a newly developed approach which provides a revised estimate of this risk. Finally, a simple tabular format is used to summarise the principal recommendations from the Committee that are to be used in the new Recommendations.
In addition to the major work on the Foundation Document, Working Parties will continue:

- to review published epidemiological studies,

- to survey developments in cell and molecular biology relevant to the effects of ionising radiation,

- to identify cells at risk,

- to provide evidence of dose and dose-rate effects from animal studies,

- to advise on genetics risks in relation to both mendelian and multifactorial disorders, and

- to survey the evidence of synergism or additivity between the effects of ionising radiations and chemical carcinogens on cells and tissues.

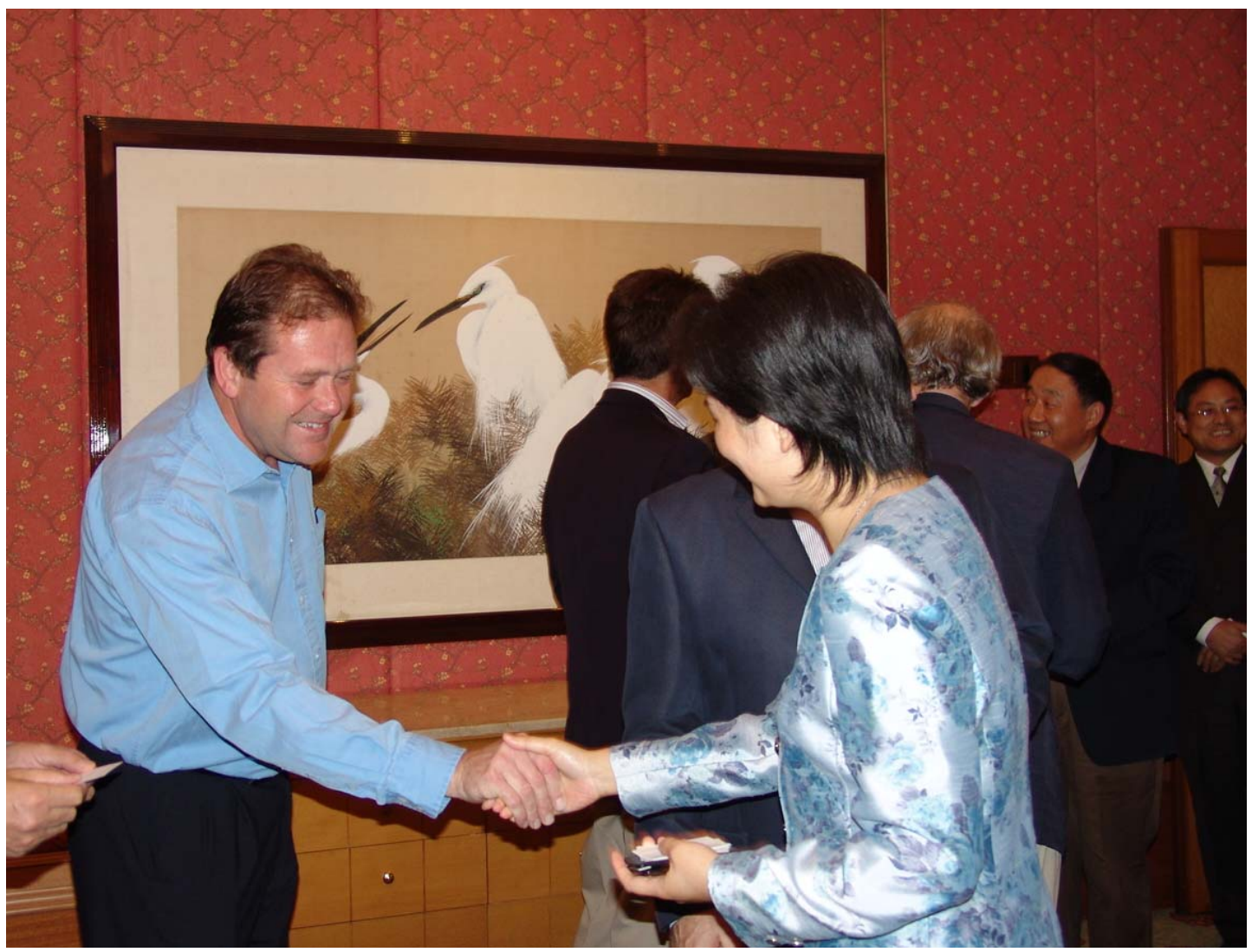

Professor Roger Cox, Chairman of Committee 1, shaking hands with the Vice-Mayor of Suzhou (P.R. China), Ying TAN. ICRP greatly appreciates the generous hospitality shown by organisations and governments hosting meetings all over the world, and makes a point of being available at such occasions for discussions with local experts and interested parties. 


\section{Committee 2 (Doses from Radiation Exposures):}

Committee 2 has the responsibility for establishing dose coefficients for internal and external exposures. This involves developing the dosimetric models to be used in the calculations.

Like Committee 1, Committee 2 has had a Foundation Document underpinning the coming next Recommendations as one of its most important tasks. The Committee 2 Foundation Document will deal with dosimetric quantities used in radiological protection, thus effectively updating Annex A of the 1990 Recommendations.

An early draft of this document had been circulated for peer review among experts, and at its meeting in Beijing, the Committee discussed the comments received and numerous proposals from within the Committee in considerable detail. An updated draft is being prepared for approval in due course for public consultation.

A document on doses to infants from radionuclides ingested in mothers' milk will complete the set of reports of Committee 2 on dose coefficients for members of the public. It will comprise a main text and a series of element specific sections giving reviews of biokinetic data and models for 35 elements. It will also include a brief discussion of the doses calculated for selected radioisotopes.

The document had been subjected to public consultation and peer-reviewed by senior experts. An important observation was that under certain circumstances, the dose to an infant from a mother holding the infant, due to activity retained in the mother, could exceed that from activity transferred to the child in mothers' milk. A final version of the document, where this aspect was also taken into account, had been prepared and will be published shortly.

A new dosimetric model, 'HAT', for the human alimentary tract has been developed to replace the gut model in Publication 30 and used for the calculation of all subsequent dose coefficients.

Drafting of this report advanced considerably during 2004, and the text was subjected to extensive peer review. Committee 2 reviewed and edited the draft at its meeting in Beijing, so that a final version could be prepared for approval for publication in 2005.

The assessment of doses from radiopharmaceuticals is carried out by a standing Task Group of Committee 3, with membership from Committee 2. This ensures that the models used are consistent with the work in Committee 2. The Task Group has been involved in preparing a series of addenda to Publication 53 giving dose coefficients for a range of radiopharmaceuticals. An Addendum 8 to ICRP Publication 53 was prepared in 2004 for interim posting on the ICRP web site. This will discuss an updated model for ${ }^{11} \mathrm{C}$ and generic models for ${ }^{18} \mathrm{~F}$ - and ${ }^{123} \mathrm{I}-$ labelled radiopharmaceuticals.

A comprehensive revision of advice on dose assessment and monitoring for occupational intakes of radionuclides is being prepared. It is intended to replace ICRP Publications 30, 54, 68 and 78 by a single series of reports that will cover both dosimetry and bioassay interpretation. Work on this project continued in 2004; it is expected that a reasonably complete draft will be available in 2007- 
An intractable issue in internal radiation dosimetry has been the discrepancy between the dose from exposure to radon inferred from epidemiology and the higher dose calculated using the human respiratory tract model (HRTM). This still remains to be resolved; various options were discussed by Committee 2 in 2004.

The development of reference voxel phantoms based on medical CT and MRI imaging data continued. In this process, data obtained from real individuals are manipulated to make the various organ sizes agree with those of the 'Reference Male and Female' of ICRP Publication 89. This scaling is not a simple task, as the relationships of the various organ masses are non-linear. The anatomical aspects of the updated phantoms have now been reviewed in detail by medical experts. It is hoped that the new phantoms will be ready for formal approval and adoption in the near future.

A joint Task Group of ICRP and ICRU, the International Commission on Radiation Units and Measurements, is assessing reference doses from cosmic ray exposure to aircrew. The Task Group is compiling and evaluating results from measurements and calculations of effective doses and ambient dose equivalent rates for exposure in aircraft at aviation altitudes, for the range of geomagnetic latitudes of relevance and as a function of time within the solar cycle. A partial draft report was prepared in 2004, but a final draft will have to be compiled after ICRP has taken a final decision on the weighting factors to be used in the next Recommendations.

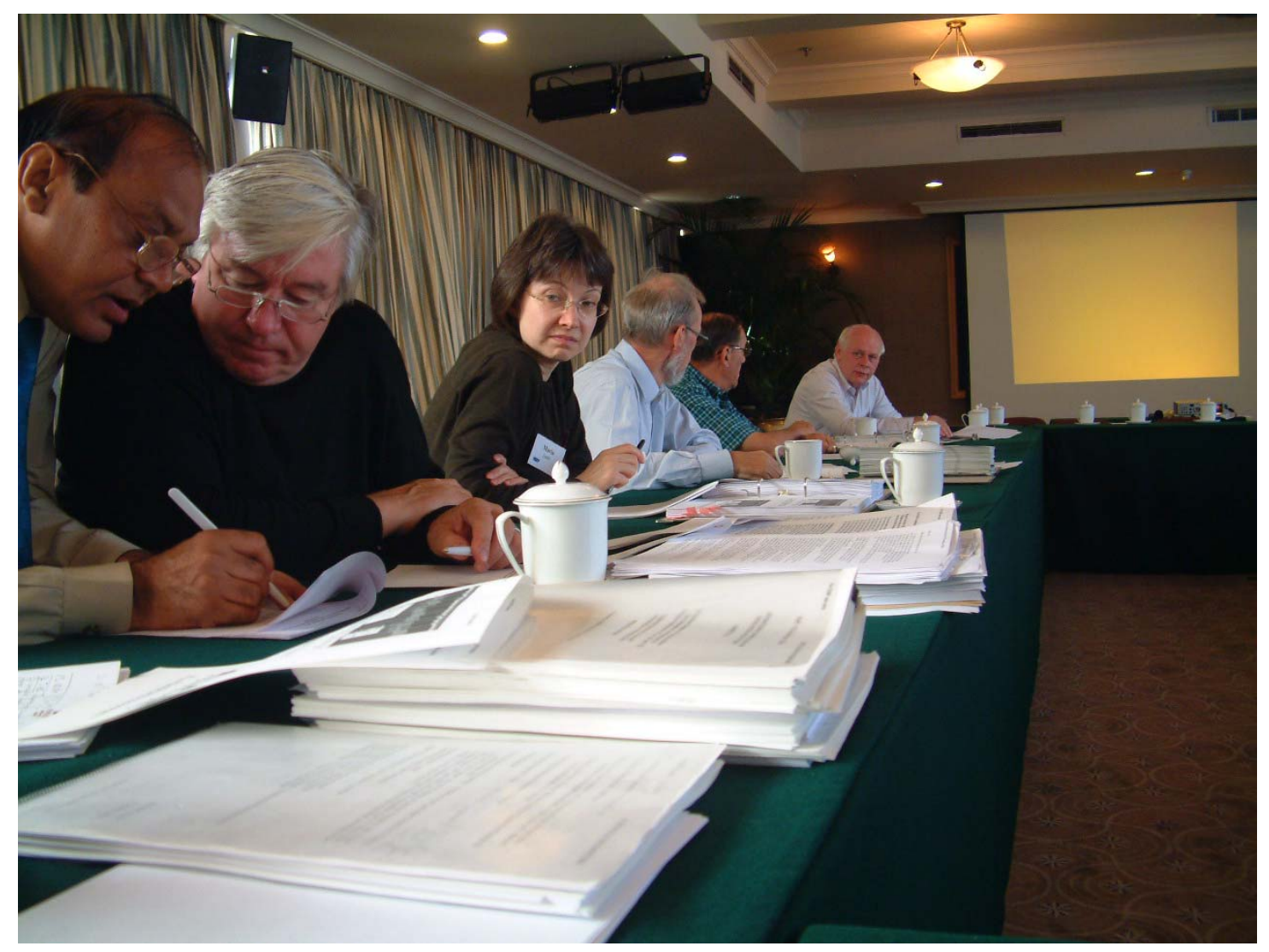

Considerable amounts of draft material are reviewed during a Committee meeting (here: C2, Beijing). From left, Drs A Pradhan, H Paretzke, M Zankl, G Dietze, D Taylor, and H Menzel. 


\section{Committee 3 (Protection in Medicine):}

The responsibility of Committee 3 is radiological protection and safety in medicine.

The 2004 meeting of Committee 3 was attended by 14 full members plus 3 observers (the International Commission on Radiological Units and Measurements, ICRU, the International Labour Organization, ILO, and the International Standardization Organization, ISO).

Some aspects on the annual medical examination for workers with ionising radiation were discussed and the criteria of the ILO were presented. ILO would be open to recommendations on scientific justification on medical surveillance of persons exposed to ionising radiation. ILO also would be happy to participate in efforts.

A draft on 'Radiation safety aspects of Brachytherapy for prostate cancer using permanently implanted sources' was presented and accepted for forwarding to the Main Commission for approval.

The draft Recommendations of the ICRP were discussed. The Committee had no major objections, but made several suggestions, e.g.:

- Reinforce aspects of training for medical exposures, quoting all documents produced by C3 in recent years;

- Clarify the changes in some risk factors, especially breast and gonads;.

- Clarify the quoted age for workers: 20 to 64 years;

- Consider re-stating that effective doses should not be recalculated retrospectively with the new weighting factors;

- Update the risk for cataracts induced by radiation;

- Clarify the concept of constraints;
- Clarify definition of medical exposure re patient vs occupational

The following Task Groups (TG) and Working Parties (WP) were agreed by Committee 3:

- TG: Radiation protection for cardiologists performing fluoroscopically guided procedures; C Cousins (1 year);

- TG: Radiation protection issues of modern radiotherapy techniques, JM. Cosset (Joint project with ICRU) (3 years);

- TG: Dose to patients from radiopharmaceuticals, S Mattsson (continuing standing TG);

- WP: Protecting children: Diagnostic techniques involving ionising radiation, $\mathrm{H}$. Ringertz ( $2-3$ years);

- WP: Exposure of hands to ionising radiation while preparing and handling radiopharmaceuticals, J Linecki (1-1.5 years);

- WP: Radiation protection training for clinical personnel that use ionising radiation in medicine, E Vañó (2-3 years);

- WP: Medical-Legal exposures using ionising radiation without direct benefit to the exposed individual, C Sharp (2-3 years);

- WP: .Medical examinations and followup of persons accidentally or occupationally exposed to ionising radiation, $\mathrm{F}$ Mettler (1.5 years);

- WP: Medical screening of asymptomatic persons using ionising radiation, $F$ Mettler (1.5 - 2 years);

- WP: Dose management in multi-detector computed tomography (CT), M Rehani (2 years).

A draft of the document 'Radiation dose to patients from radiopharmaceuticals' was presented by Sören Mattsson and approved by the Committee. The document contains relevant changes with practical implications in comparison 
with some of the previous ICRP advice in Publications 52 and 80 (especially in relation with the periods of breast feeding interruption), so a paragraph highlighting this aspect will be prepared for consideration by the Main Commission.

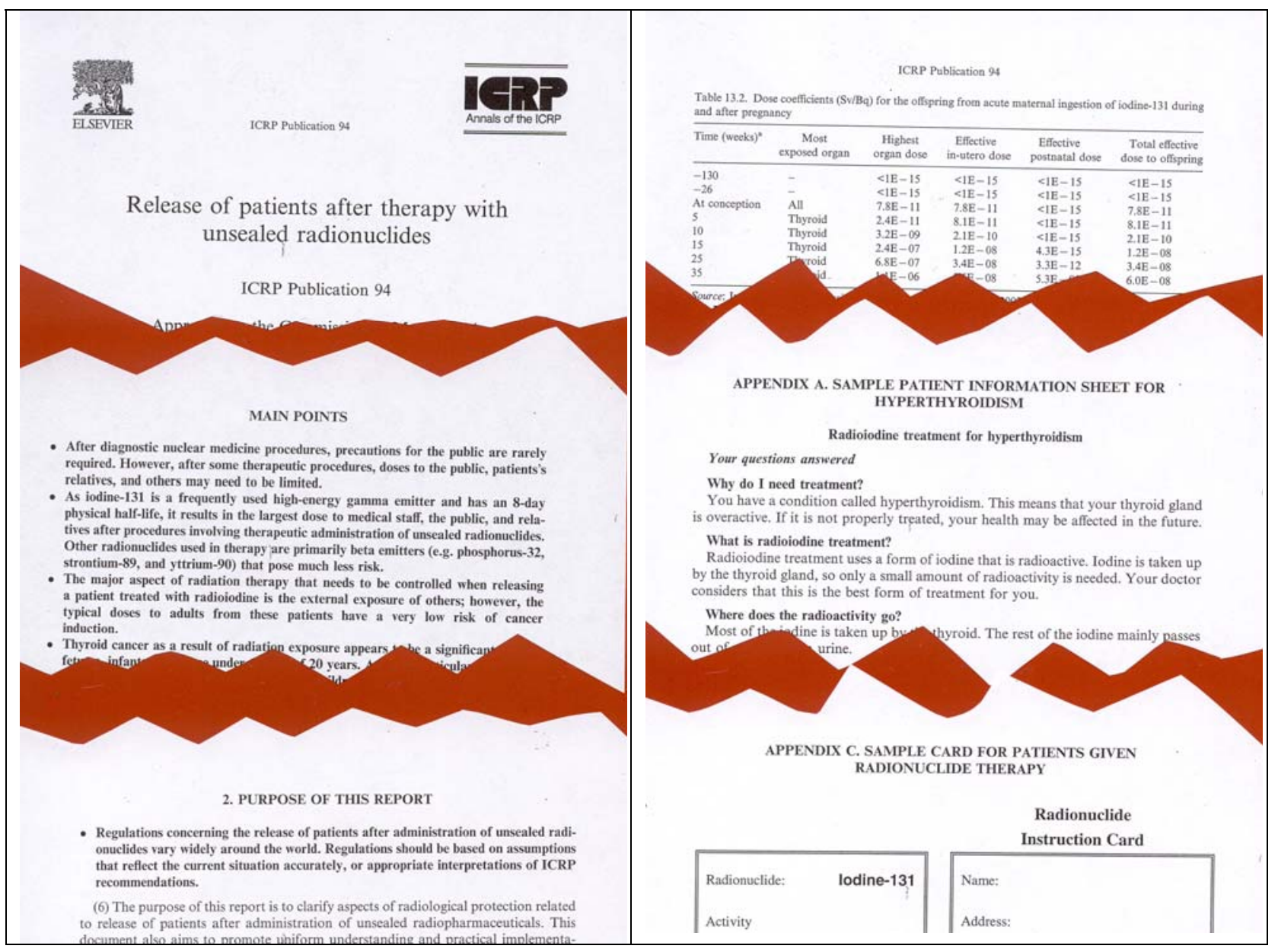

Among the prolific output in recent years from ICRP Committee 3 we find ICRP Publication 94 (2004) on release from hospital of patients who have been treated with radioactive substances and who are therefore in a sense sources of irradiation that could affect other persons. The medically oriented reports of Committee 3 contain the same type of tables, equations, etc, typical of all scientific reports; in addition, they always summarise clearly upfront the main points made and the purpose of the report. Usually, there is also practical advice intended for immediate practical implementation. 


\section{Committee 4 (Application of the Commission's Recommendations):}

ICRP Committee 4 has the responsibility to consider the practical application of the Commission's recommendations. The Committee also acts as a major point of contact between the ICRP structure and other international organisations and professional bodies concerned with protection against ionising radiation.

Committee 4 is preparing two Foundation Documents for the new Recommendations. These are on optimisation of protection and on the specification of an 'exposed individual' for limitation of releases of radiation that could affect members of the public.

Optimisation: Optimisation of protection is an important component of a successful radiological protection programme. It involves evaluating and, where practical to do so, incorporating measures that tend to lower radiation doses to members of the public and to workers. Committee 4 now wishes to emphasise that conceptually, the optimisation of protection is broader, in that it entails consideration of the avoidance of accidents and other potential exposures; it incorporates a range of qualitative and quantitative approaches and involves adopting a safety culture.

Both the operators and the appropriate national authority have responsibilities for optimisation. Operators design, propose and implement protection policies using optimisation, and then use experience to further improve it. Authorities require and promote optimisation and may verify that it has been effectively implemented.

Optimisation of protection must continue during the operational and termination phases. For emergencies, opti- misation should be used at the planning phase to determine levels for intervention actions. During any actual emergency, it is applied in a flexible manner to allow for the prevailing circumstances. In existing controllable situations, optimisation is used as part of the process to select and implement protective actions.

The basic role of the optimisation of protection is to foster a 'safety culture' and engender a state of thinking in everyone involved in the control of radiation exposures, such that they are continuously asking themselves the question, 'Have I done all that I reasonably can to reduce these doses?'. Clearly, the answer is a matter of judgement and necessitates cooperation between all concerned parties and, as a minimum, the operating management and the regulatory agencies.

The involvement of stakeholders, a term used by the Commission in Publication 82 to mean those parties who have interests in and concern about a situation, is an important input to optimisation. While the extent of stakeholder involvement will vary from one situation to another, it is a proven means to resolve conflicts among competing interests, to share understanding with both workers and the public, and to build trust in institutions.

In addition to the reduction of the magnitude of individual exposures, there is the additional expectation to reduce the number of exposed individuals. The comparison of protection options for the purpose of optimisation involves consideration of the distribution of the doses within all the groups of exposed individuals. No single characteristic of this distribution is adequate for making these comparisons. 
A particular issue concerns the comparison of the distribution of the exposures over long time periods and distant populations. In the past, the way to take into account this type of distribution was the collective effective dose concept defined in Publication 60 as the product of the arithmetic mean dose and the number of exposed individuals. However, the integral of low individual exposures over large populations, large geographic areas and over large periods of time may aggregate information excessively.

The Commission considers that collective dose, as defined above, is not to be used on its own in making decisions, because it may aggregate information excessively. The Commission now recommends the maintenance of the distribution of individual doses related to a given source in components reflecting the characteristics of the exposed individuals and the time and space distributions of exposures, relevant for the decision making process considered. This disaggregating process results in a 'dose matrix' which is defined on a case by case basis. The Foundation Document will develop the use of this matrix approach.

The individual: The application of a constraint relates to protection of an individual from a source. In general, especially for public exposure, each source will cause a distribution of doses over many individuals, so it will be necessary to use the concept of a critical group to represent the most exposed individuals. The second Foundation Document from Committee 4 addresses this issue.

The concept of critical group, as defined in previous Commission Publications 43 and 60, is retained. Such a group is chosen to be representative of the most highly exposed individuals as a result of the source. Its characteristics should be derived from the mean of a homogeneous and sustainable group. Additionally, it is important that in calculations of doses, the average habits in the critical group are used, and not the habits of a single extreme individual. The critical group may, however, include some individuals with extreme or unusual habits and should be selected such that all relevant habits are taken into account.

For the purpose of assessing compliance with the specified constraints, the Commission is considering the use of a selected set of age-related dose coefficients and age-averaged habit data for the individual in the case of continuing exposures of the public. The dose per unit intake to individuals can vary in agespecific manner due to different parameters. The Commission is investigating whether this method has advantages over the agespecific dose coefficients combined with age-specific intakes. Methods to assess such doses will be addressed in the Committee 4 Foundation Document.

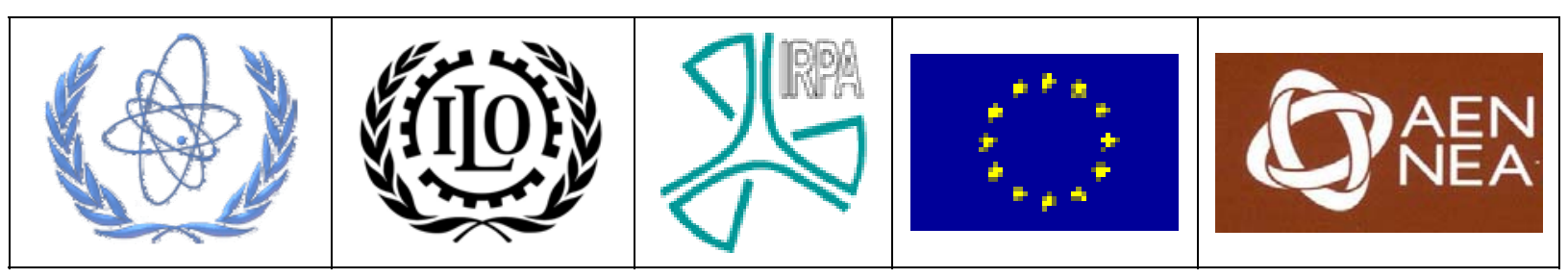

Committee 4 is the major point of contact between ICRP and international organisations, among others the International Atomic Energy Agency (IAEA), the International Labour Organization (ILO), the International Radiation Protection Association (IRPA), the European Commission (CEC), and the OECD Nuclear Energy Agency (NEA).Additional organisations observe primarily the other Committees, but may also be interested in C4 activities. 


\section{The Main Commission:}

The Main Commission met in Vienna, Austria, in April and then again in Beijing and subsequently Suzhou, China, in October.

At the Vienna meeting, the major item on the agenda was a final review of the draft next Recommendations before presenting the draft at the Madrid Congress of the International Radiation Protection Association and thereafter posting it at the ICRP web site for world-wide public consultation. The Commission went over the draft in considerable detail and made many editorial amendments.

At that meeting, several other documents in preparation were also reviewed. These were:

- Doses to the infant from radionuclides ingested in mothers' milk; this had already been approved in principle at the 2003 Buenos Aires meeting, and the discussion focused on how consultation comments had been taken into account. The Commission also requested that a set of conclusions be circulated for approval by postal ballot.

- Protecting people against radiation exposure in the aftermath of a radiological attack; as a result of the discussion, the draft was approved for public consultation via the ICRP web site.

- Low-dose extrapolation of radiationrelated cancer risk; a number of amendments were suggestedas a preparation for public consultation.

- Dosimetric quantities for use in radiological protection; a number of amendments were suggested for the next draft version.
- Defining the exposed individual; the Commission provided advice to the Task Group on outstanding issues.

- Optimisation of radiological protection; the Commission provided advice to the Task Group on outstanding issues.

Furthermore, the Commission decided to invite Dr R Julian Preston to be the next Chair of ICRP Committee 1 from 1 July 2005, and to invite Dr Hans-G Menzel to be the next Chair of ICRP Committee 2 from 1 July 2007. Both of them were also invited to participate as observers at MC meetings until they take over their respective Committees.

At the time of the meetings in China, the draft Recommendations were on the ICRP web site for an ongoing public consultation, so the discussion of those Recommendations was relatively brief. However, several other documents were discussed in some detail:

- Low-dose extrapolation of radiationrelated cancer risk; this report was now approved for public consultation.

- Optimisation of radiological protection; this was reviewed and a number of amendments were suggested.

- Defining the exposed individual; this was approved for public consultation.

- Radiation safety and release of patients after therapy with permanently implanted sources; this report was approved for publication.

- Protecting people against radiation exposure in the aftermath of a radiological attack; this report was approved for publication.

- Dosimetric quantities for use in radiological protection; this draft was reviewed and a number of amendments were suggested. 
- Health risks attributable to radiation; this draft was reviewed and a number of amendments were suggested.

The Commission also approved the formation of joint Task Group with ICRU, the International Commission on Radiation Units and Measurements, to revise ICRP Publication 44 on protection of the patient in radiotherapy.
Finally, the Commission discussed broadly the membership of the 2005 - 2009 Committees, and took decisions on most of the new Committee members to participate in these Committees. It also decided to return to this issue at its next, March 2005, meeting in order to make final membership decisions.

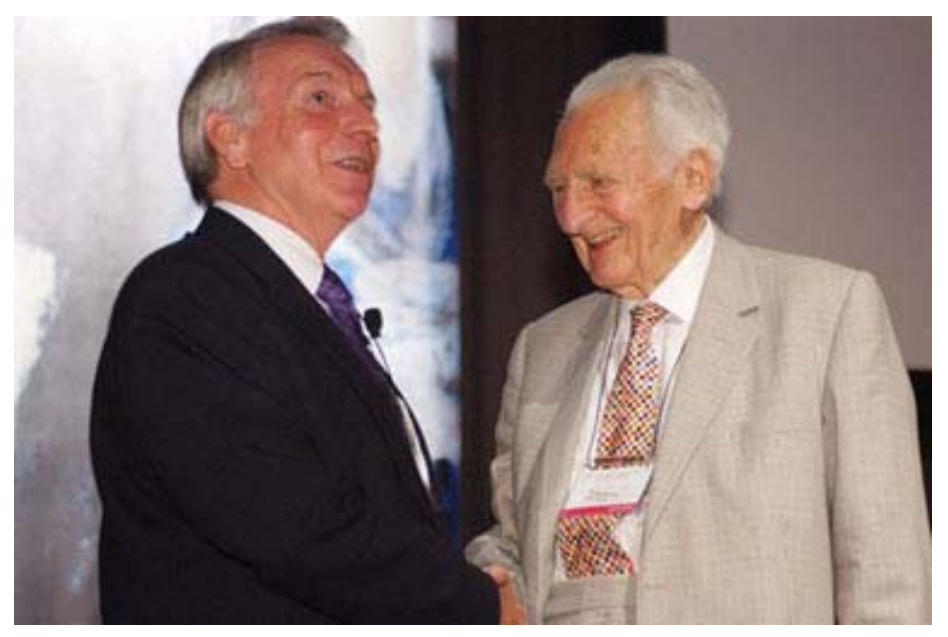

Professor Sir Richard Doll (right) is congratulated by the ICRP Chairman, Professor Roger Clarke, after having received the Gold Medal for Radiation Protection of the Royal Swedish Academy of Sciences. The $11^{\text {th }}$ Congress of IRPA, the International Radiation Protection Association, was not only the venue where the draft next Recommendations of ICRP were launched publicly, but also the occasion of a very pleasant duty for the ICRP Chairman: ICRP acts as a nominating committee for this Gold Medal, and the ICRP Chairman presents it on behalf of the Academy at the IRPA Congresses.. 


\section{The Scientific Secretariat}

The Scientific Secretariat is currently situated in Stockholm, Sweden. The seat of ICRP remains in the United Kingdom where ICRP is a Registered Independent Charity.

Tasks of the Secretariat include preparations for and organisation of meetings, final editing of reports for publication in the Annals of the ICRP, maintenance of contacts with all collaborating organisations, and administrative issues.

The Secretariat also devoted an increasing part of its efforts to running the ICRP Internet web site. Apart from providing general information about ICRP, the web site has proved particularly useful when ICRP wants to consult on its own draft documents. A drawback was that the resources of the Secretariat were not always quite commensurate with the demand for information and assistance generated through the web site, so that at times, considerable delays in attending to queries from the public were inevitable.

The diagram below shows that the number of files opened increases each year, and that this is primarily because there are more and more 'general' enquiries (from members of the public).

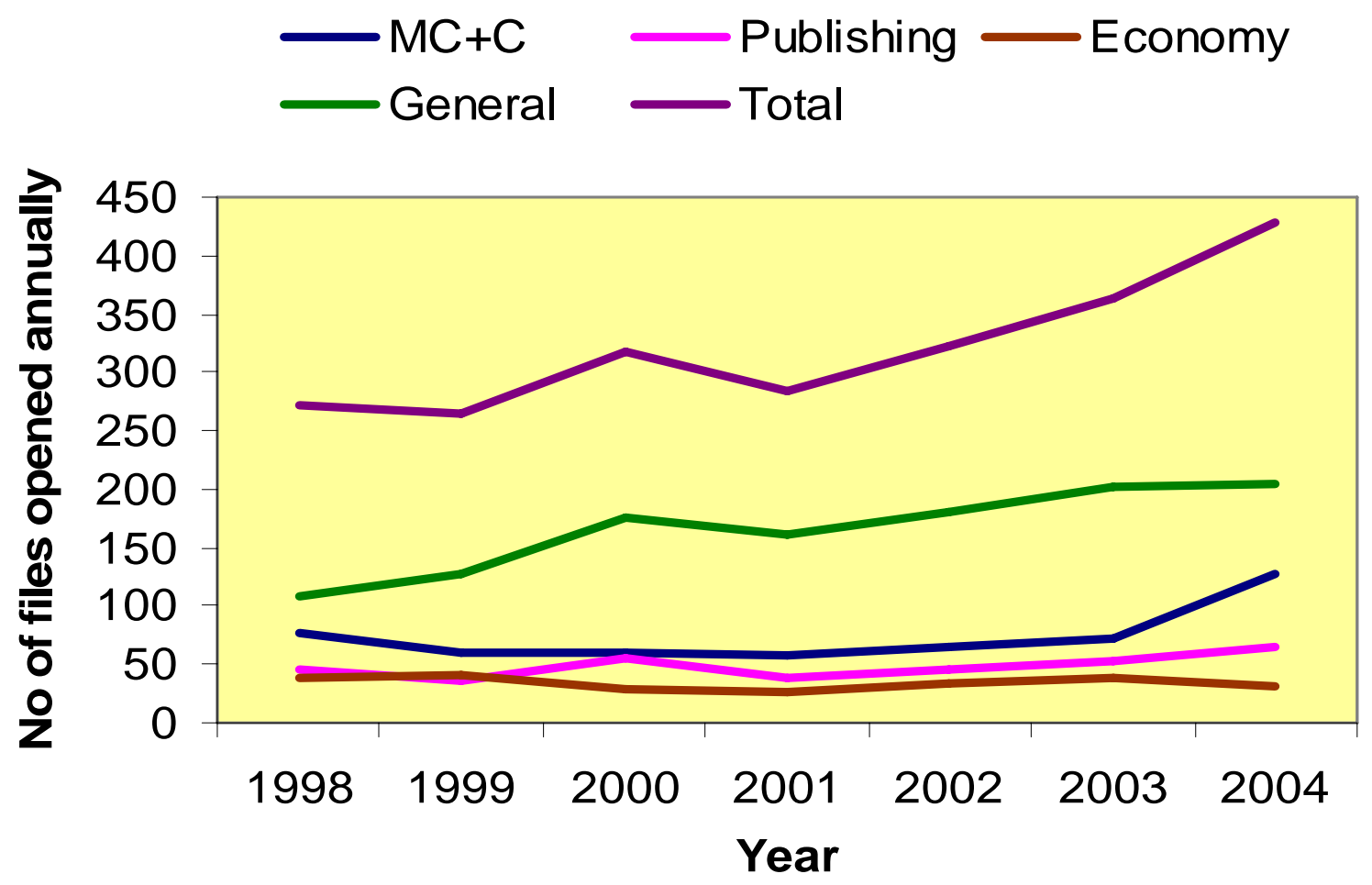




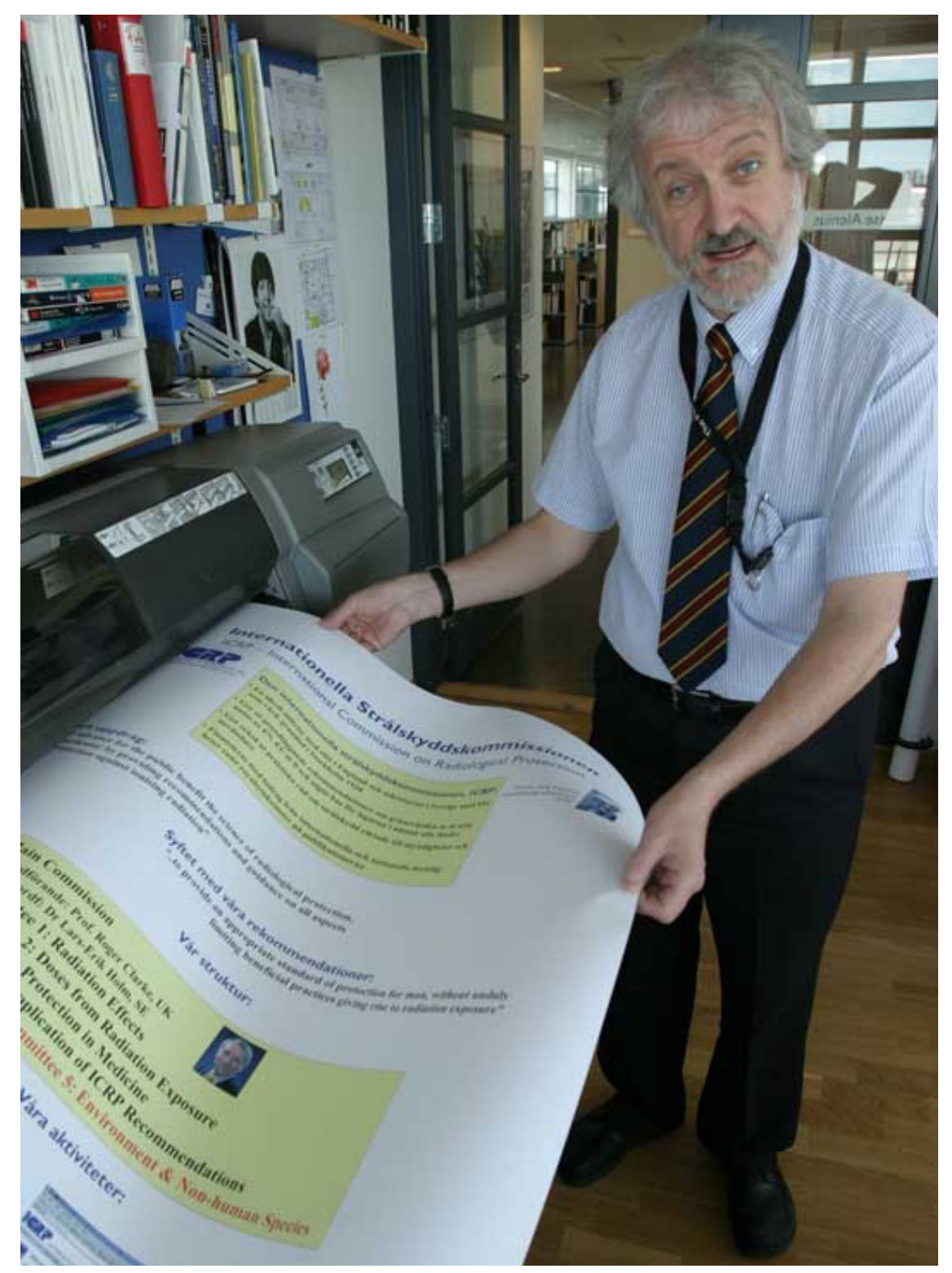

One of the tasks of the Scientific Secretary is to represent the Commission and make various presentations at scientific meetings. Here, Dr Jack Valentin is printing a poster for a presentation of ICRP and its duties in Sweden.. 


\section{Contacts, Meetings, etc.}

As usual, numerous different contacts were maintained, formally and informally, during the year.

In addition to the many instances where the Chairman, Professor Clarke, represented the Commission as described in the Foreword, the Vice-Chairman, Dr Holm, the Scientific Secretary, Dr Valentin, and members of the Commission represented ICRP in meetings of various kinds.

Thus, contacts were held and continued with IAEA, the International Commission on Radiation Units and Measurements (ICRU), the International Radiation Protection Association (IRPA), the International Society for Radiology, the OECD Nuclear Energy Agency, the United Nations Scientific Committee on the Effects of Atomic Radiation (UNSCEAR), and many other organisations.

The persons mentioned also took part in many meetings with national regulatory organisations, research establishments, and professional societies.
During the meetings of the Main Commission in Beijing and in Suzhou, China, in October, informal meetings were arranged with the considerable local community of experts interested in various aspects of ionising radiation and radiological protection. Furthermore, members of the Main Commission and the Committees as well as the Scientific Secretary visited many additional places in China for information about ICRP and its activities.

ICRP also continued its relationship with the International Electrotechnical Commission (IEC) and the International Standards Organization (ISO), primarily through exchange of draft reports and information. On a number of occasions when ICRP was unable to send a formal representative, we arranged to obtain observers' reports so as to keep abreast with developments.

There was also a brisk demand for informal enlightenment and information via telephone, e-mail, and regular mail to the Secretariat. 


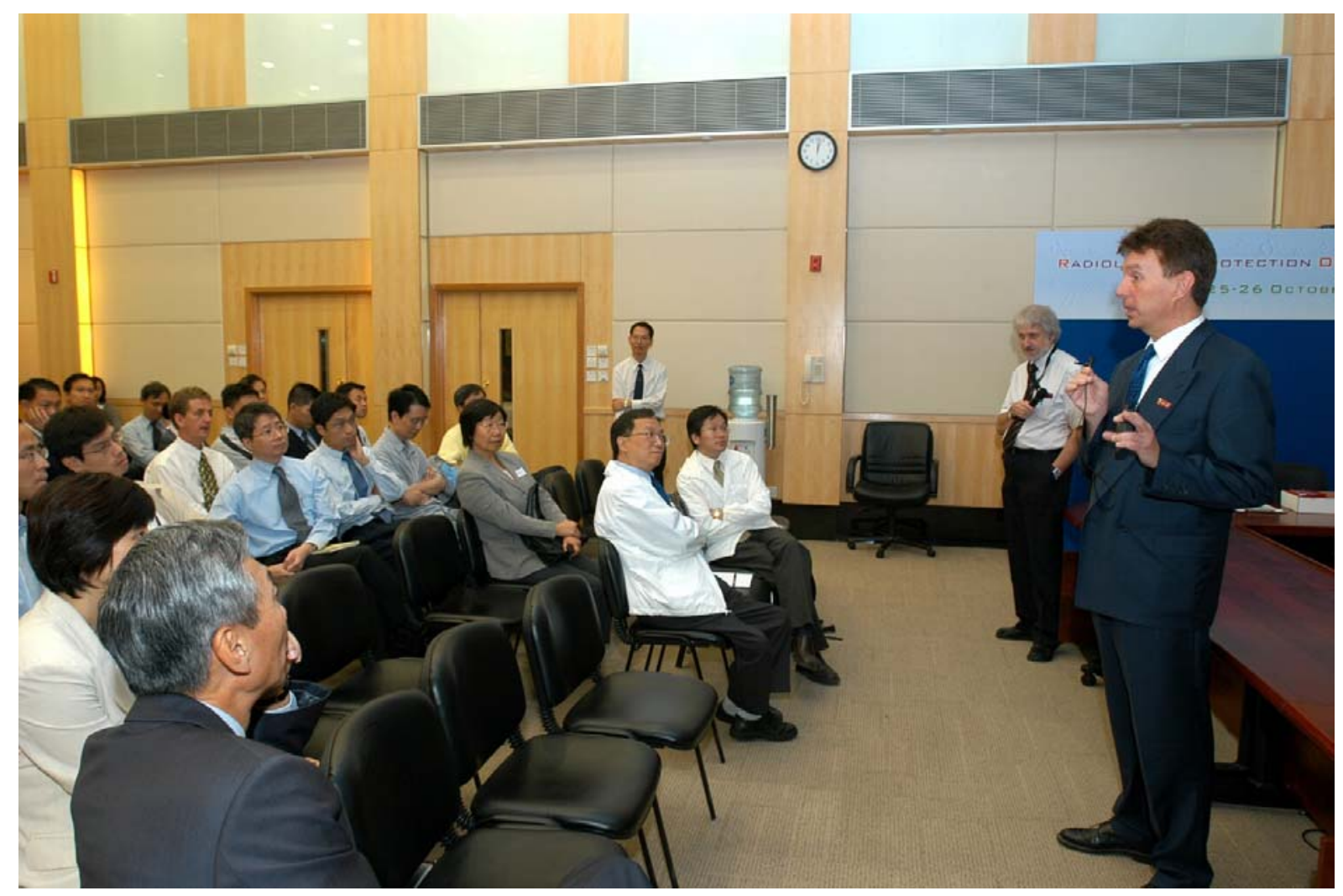

After the meetings of the Committees and the Main Commission of ICRP in Beijing and Suzhou, several ICRP members presented ICRP at various venues. Here, the Vice-Chairman, Dr Lars-Erik Holm (standing in the foreground) and the Scientific Secretary, Dr Jack Valentin (standing in the background) have met to lecture in Hong Kong after having followed different itineraries through China. 


\section{ICRP Publications, etc., printed in 2004}

ICRP. Managing patient dose in digital radiology. ICRP Publication 93. Annals of the ICRP 34 (1), Elsevier Science Ltd, Oxford, UK.

ICRP. Release of patients after therapy with unsealed radionuclides. ICRP Publication 94. Annals of the ICRP 34 (2), Elsevier Science Ltd, Oxford, UK.

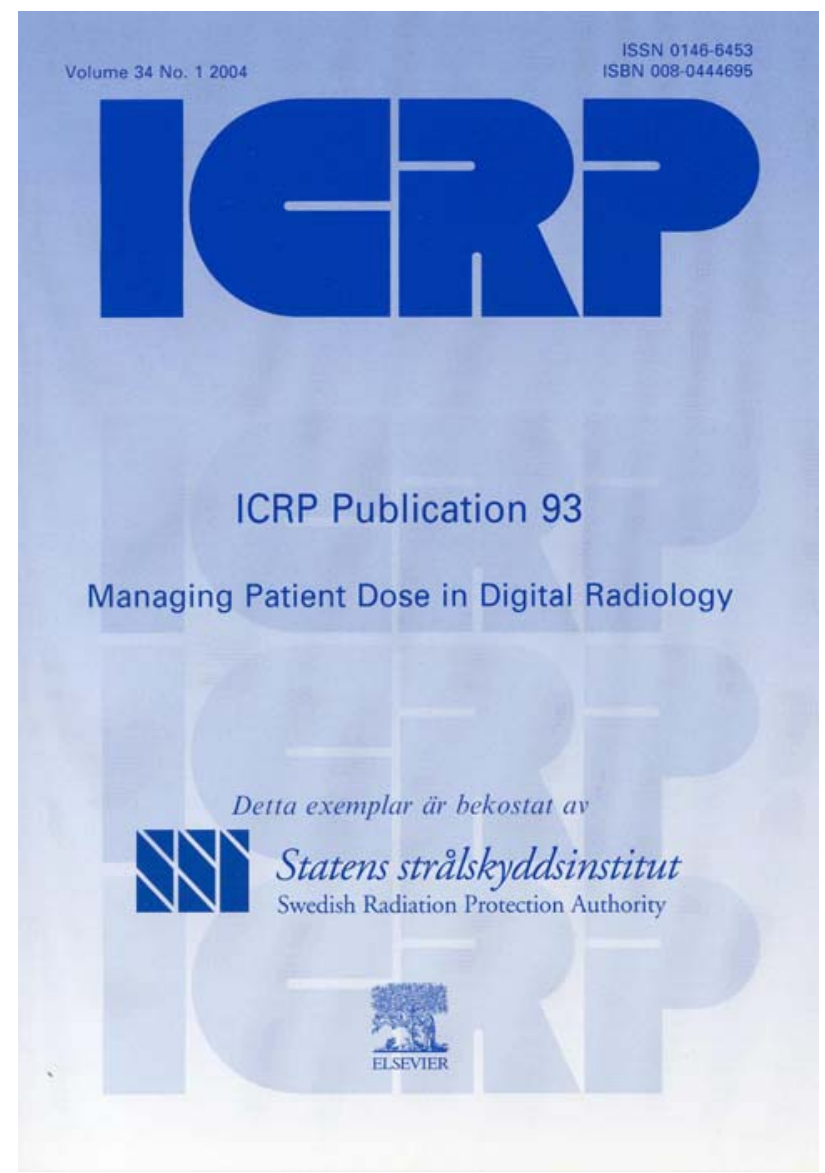

ICRP Publications can be obtained through subscription (in printed format and/or as an electronic file) or individually as printed books or as files for downloading (from www.sciencedirect.com. ) An increasingly popular option is for organisations to buy 'sponsored copies' for distribution, if desired with their own logo overprinted. The Swedish Radiation Protection Auhtority, and several others, bought a number of copies of ICRP Publication 93 for distribution for free to licensees. 


\section{Contact Information}

The address of the Commission’s Scientific Secretary, Dr J Valentin, is

International Commission on Radiological Protection

ICRP

SE-171 16 Stockholm

Sweden

Telephone: $\quad+4687297275$

Telefax: $\quad+4687297298$

E-mail:_ jack.valentin@ssi.se

Web site: www.icrp.org

ICRP Publications are available from reputable booksellers or directly from the Commission's publishers, Elsevier Science:

Web site, world-wide: www.elsevierhealth.com/journals/icrp

For customers in the Americas, the Regional Sales Office in New York, Telefax: $\quad+12126333680$

E-mail: $\quad$ usinfo-f@elsevier.com

For customers outside the Americas, the Regional Sales Office in Amsterdam,

Telefax: $\quad+31204853432$

E-mail: nlinfo-f@elsevier.nl
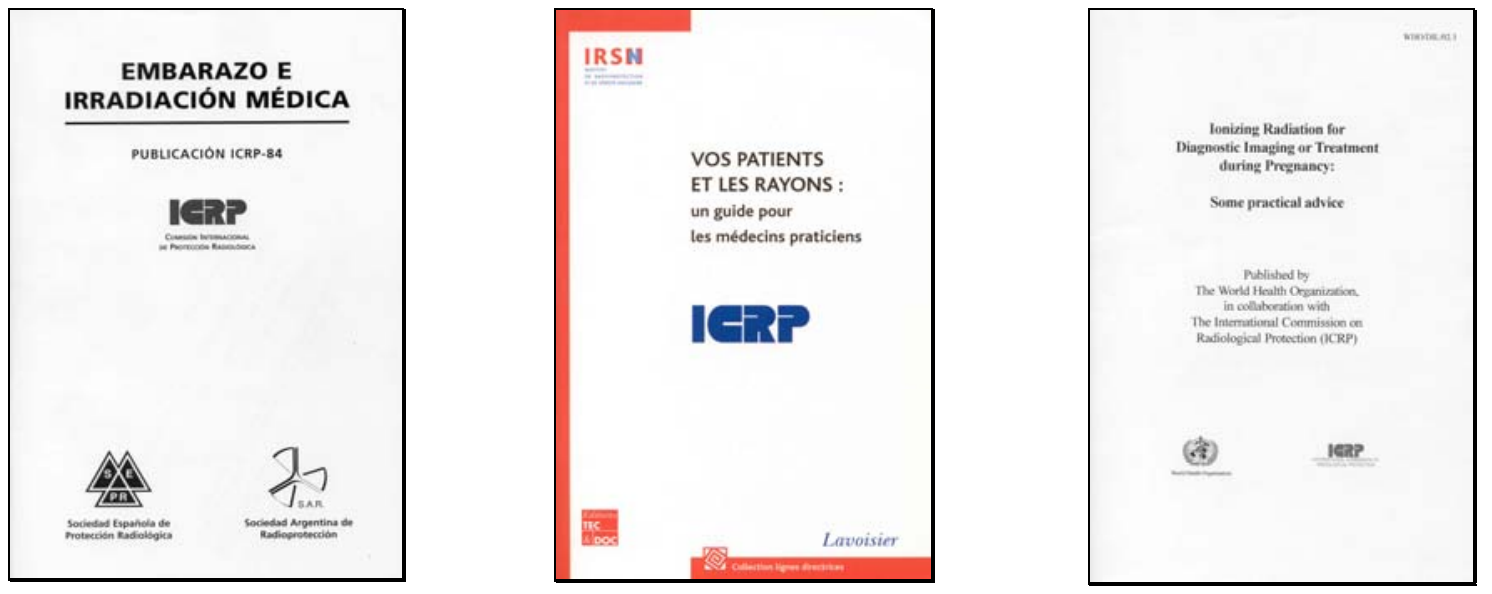

ICRP encourages translation of its reports (left: Spanish version of Publication 84; centre:

French version of Supporting Guidance 2), and often abstains from any royalty on such translations. Through the HINARI initiative ( www.healthinternetwork.net), there is free access to ICRP reports for the 69 poorest countries in the world. Through co-operation with WHO, it has also been possible to disseminate certain reports for free in regions where otherwise it would be difficult to obtain ICRP documents (right: WHO adapted version of Publication 84 for distribution in Africa only). 


\section{Organisations providing grants to ICRP in 2004}

Unrestricted funds totalling 300422 US dollars were received from:

CEC;

IAEA;

ISR;

OECD/NEA;

Canada: CNSC and Health Canada;

Denmark: NBH

France: IRSN

Germany: Bundesmin UNR;

Japan: JAERI and PNC;

Spain: CSN;

Sweden: Min. Env.;

USA: EPA, NRC.

No restricted funds were received in 2004. 


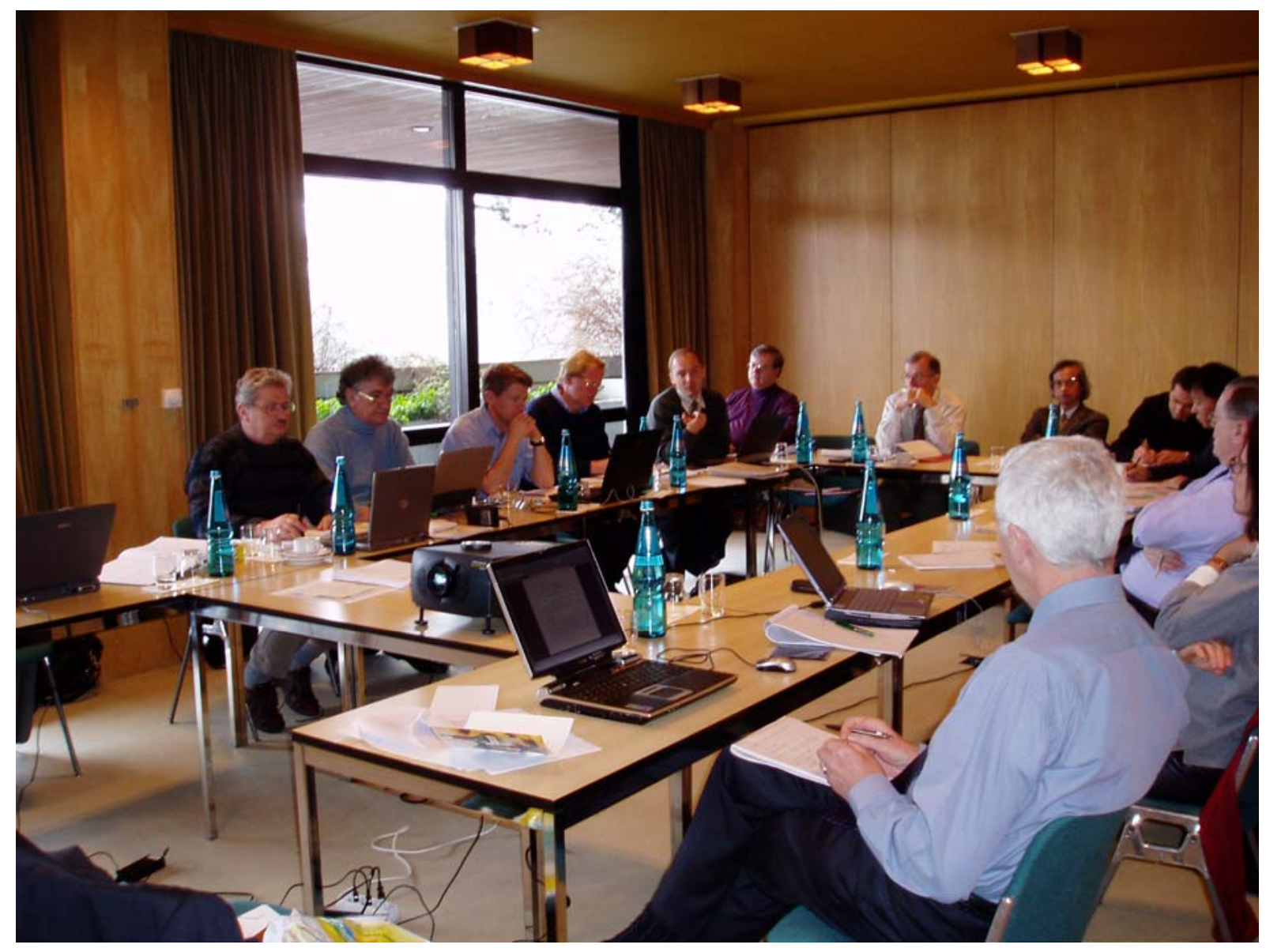

The actual drafting of ICRP reports takes place in the Commission's Task Groups - here, Task Group No. 21 INDOS on internal dosimetry, a Committee 2 standing project, at its meeting in Berchtesgaden, Germany, in 2004.

. The unpaid volunteer work that goes into the drafting and editing of ICRP reports represents many man-years annually. The value of this benefit-in-kind cannot easily be expressed in exact monetary terms. However, it is certainly orders of magnitude bigger than the Commission's budget, which represents direct meeting and secretariat costs only. 


\section{Composition of the International Commission on Radiological Protection and Committees, 2001 - 2005}

\section{$\underline{\text { MAIN COMMISSION }}$}

R H Clarke (Chairman)

R Alexakhin

$\mathrm{J}$ D Boice

R Cox (Chairman C1)

G J Dicus

A J González

L-E Holm (Vice-Chairman)

F A Mettler (Chairman C3)

Y Sasaki

C Streffer (Chairman C2)

A Sugier

B C Winkler (Chairman C4)

Z Q Pan

Emeritus Members:

D Beninson (elected in 2001)

H J Dunster

B Lindell

W K Sinclair

L S Taylor

Scientific Secretary:

J Valentin
COMMITTEE 1 (Radiation Effects)

R Cox (Chairman)

A Akleyev

M Blettner

J Hendry

A Kellerer

C Land

J Little

C Muirhead (Secretary)

O Niwa

D Preston

J Preston

E Ron

K Sankaranarayanan

R Shore

F Stewart

M Tirmarche

R Ullrich (Vice-Chairman)

P-K Zhou

COMMITTEE 2 (Doses from Radiation Exposure)

C Streffer (Chairman)

M Balonov

B Boecker

A Bouville

G Dietze

K F Eckerman

F A Fry

J Inaba

I Likhtarov

J Lipsztein

H Menzel

H Métivier

H Paretzke

A S Pradhan

J Stather (Vice-Chairman)

D M Taylor (Secretary)

Y Zhou 
Table 2 cont'd: 2001-2005 members

COMMITTEE 3 (Protection in Medicine)

F A Mettler (Chairman)

J-M Cosset

C Cousins

M Guiberteau

I Gusev

K Harding (Secretary)

M Hiraoka

J Liniecki (Vice-Chairman)

S Mattsson

P Ortiz-Lopez

L Pinillos-Ashton

M Rehani

H Ringertz

M Rosenstein

C Sharp

E Vañó

W Yin
COMMITTEE 4 (Application of ICRP

Recommendations)

B C Winkler (Chairman)

E d'Amato

D Cancio

M Clark (Secretary)

D Cool

J Cooper

T Kosako

J-F Lecomte

J Lochard

G C Mason (Vice-Chairman)

A McEwan

M Measures

M Savkin

J E Till

K Ulbak

W Weiss

Y Xia

C Zuur 